\title{
Employability Skills in Health Services Management: perceptions of recent graduates
}

\author{
D G Messum, L M Wilkes, D Jackson and K Peters
}

\begin{abstract}
Background: Employer skill requirements of graduates are monitored by Graduate Careers Australia, but health services management (HSM) specific employability skills (ES) perceived by graduates to be important on the job and their perceptions of skills they need to improve are not well reported. Academics need this feedback to improve course employment outcomes by helping current students identify and articulate appropriate competencies to potential employers. Also teaching of industry requirements can help improve job matching for employers.
\end{abstract}

Method: Recent graduates working in HSM in New South Wales, Australia were surveyed to rate ES for importance and rate their own skill levels on the same items. The gap between these two ratings was identified for $44 \mathrm{ES}$.

Results: ES important to recent graduates in rank order were: verbal communication skills, integrity and ethical conduct, time management, teamwork, priority setting, ability to work independently, organisational skills, written communication, being flexible and open minded and networking. Highest self-ratings were found for integrity and ethical conduct, ability to work independently, being flexible and open minded, tertiary qualifications, interpersonal skills, written communication skills, time management, life-long learning, priority setting and administration skills. Generally graduates rated their skills lower than their ratings of importance.

Conclusions: Recent graduates can provide valuable feedback to universities about ES required for HSM positions and identify their own skill gaps for development at work or through study. Generic skills rather than job-specific skills are what they rate as most important. Closer engagement of universities and employers is recommended especially through placements.

Abbreviations: ES - employability skills; GCA - Graduate Careers Australia; HEI - higher education institutions; HRM - human resource management; HSM - health services management; IPC - interpersonal and communication skills.

Key words: employability skills; generic skills; graduates; health managers; university.

\section{Introduction}

The aim of this study was to identify skills that recent graduates working in the field of health services management (HSM) in New South Wales Australia, perceive as important for their jobs and how they rate their own skill levels. What they find important may include technical or discipline specific skills, personal attributes and employability skills (ES). The Australian Commonwealth Department of Education Science and Training [1] has defined ES as:

Skills required not only to gain employment, but also to progress within an enterprise so as to achieve one's potential and contribute successfully to enterprise strategic directions. Employability skills are also sometimes referred to as generic skills, capabilities or key competencies. (2002 p.143) 
This definition was the preferred option because ES is the term used by industry. The term encompasses not only skills related to getting a job but also ongoing employment, understanding of which is useful not only in recruitment processes for employers, current graduates and undergraduates but also for work-based professional development. Findings can also be used to inform higher education curriculum development and help improve employment outcomes. However, it is acknowledged that ES to secure employment may be different to skills required to progress in an organisation, [2] and some skills may best be learnt on the job.

Generic ES seem more useful than job-specific skills [3] for coping with rapidly changing and complex work environments. The Australian Employability Skills Framework [4] acknowledged ES as skills and knowledge that enable employees to perform effectively in the workforce and apply technical or discipline specific skills. This report found that failure to recognise the context-dependent nature of ES, lack of explicit focus on ES in education, also measurement and assessment difficulties helped explain poor development of ES in graduates. One key intention of this paper is to make ES more visible and explicit for the field of HSM.

\section{Employers' perceptions}

Many studies have explored the views of employers about skills required on the job, but relatively few report on the views of recently employed graduates working in the field $[5,6,7]$ and no studies specific to HSM were found in the literature. Graduate Careers Australia annually conducts large scale surveys, reporting $23.4 \%$ of Australian employers indicated they had difficulty sourcing, recruiting and retaining graduates. [8] Where vacancies are advertised may help explain recruitment difficulties. Vacancy advertisements compared poorly with hiring rates for employee referrals and university placements. [8] Expectations about work readiness and employer preferences for graduates who 'hit the ground running' have also been explored. $[9,10]$ Typically generic ES have been found more important to employers rather than discipline specific skills or degree results. [11] The most important ES to employers has consistently emerged as communication skills, written and oral, but skill gaps have been noted. $[12,13,14]$ Other reported skills gaps related to integrity, teamwork, problem solving, literacy, numeracy, critical analysis skills, software skills, planning, organising and self-management. [15]

There is limited research exploring ES requirements from employers in the health arena. Messum et al 2011 [16] found that the main essential requirements advertised for HSM were interpersonal skills, experience, tertiary qualifications, knowledge of the healthcare system, teamwork, conceptual and analytical skills, computer skills, financial skills and leadership. Important to senior health managers was integrity and ethical conduct, interpersonal skills, teamwork, being flexible and open-minded, written and verbal communication skills, self-awareness, collaborative and planning skills rather than technical or discipline-specific skills. Only two common items were revealed for the top ten essential skills advertised compared with the top ten ES required by senior health managers: interpersonal skills and teamwork. [17] Specifically ES gaps in recent graduates that they supervised were reported for teamwork, written skills, collaboration, negotiation, computing and software skills (specifically use of Excel), strategic thinking, ability to scan the environment and self-awareness. [17] This study also found that health managers wanted new graduates with good self-management skills who required minimal supervision, and were self-starters with a good work ethic.

\section{Recent graduate perceptions}

Although employers have consistently rated core ES levels lower than new graduate employees' self-ratings with the exception of information technology skills, [18] it has been argued that recent graduates are well placed to identify skills important in the real world, based on employment in the field and current insight into what is valuable. [19] They can reflect industry expectations, which can be useful for future students and $\mathrm{HEl}$ curriculum development. Although the contextual nature of ES has long been recognised [4] no recent studies from graduates focusing on HSM were found in the literature.

Engagement with the concept of employability may predict development of ES as students: if they cannot see the relevance or importance of specific ES they may be less inclined to learn them and/or demonstrate them to prospective employers. [20] For example international students who failed to recognise the importance of communication skills and 'questioning accepted wisdom' exhibited higher unemployment rates. [21] Generally graduates are increasingly aware they need additional skills and attributes for career success, that a degree is not enough. $[22,23,24]$ They hold an instrumental view of ES: [7] to secure competitive advantage because a degree only confirmed the ability to be ready for further training.

ES identified by graduates as important include communication skills, teamwork, information technology, planning and organising also flexibility and adaptability, being hard working, showing commitment and dedication, 
[14] consistent with employer requirements. However, these skills were not necessarily developed at university. Rather, placements were highly valued for development of teamwork, as was being given responsibility and collaborative learning enhanced critical thinking, problem solving, decision-making and raised ethical awareness. $[7,18,21]$ Specifically, the workplace team focus was found very different to the university culture of individualised work. [21] Vocationally oriented programs, well connected to employers using assessments based on lectures, internships, written assignment and oral presentations, characterised better performing universities in terms of employment outcomes. [25] Interestingly use of multiple choice examinations negatively correlated with outcomes. [25]

Graduate perceptions of their own skill levels have been studied. $[6,7,26]$ In a survey of 36 Australian universities shortly after course completion, most full-time employed bachelor degree graduates felt that they possessed high levels of skill for learning, teamwork, problem solving and communication. [27] However, for information technology skills and initiative/enterprise only $58.9 \%$ and $57.7 \%$ respectively rated their skills highly. Three years later, ES were reported as much improved, especially self-management, initiative/enterprise, planning and organising, skills they identified as more effectively developed on the job rather than at university. [27] Some differentiation of ES best developed on the job and/or at university is needed.

\section{Purpose of this study}

The broad aim of this study was to identify the views of recent graduates working in the field of HSM about skills they need at work. More specifically this research aimed to determine the following:

- Perceptions of skills most important for work, whether job specific or generic.

- Any 'importance-performance' gaps [5] comparing importance ratings with self-ratings of skill levels, to reveal ES well developed or requiring further development.

- Where and how current employment was found.

- Best aspects of their HEl course and aspects for improvement as feedback for curriculum development.

This paper is the third stage of a doctoral triangulation study exploring ES for graduates working in HSM, undertaken with approval from the Human Research Ethics Committee University of Western Sydney, (number H9344, 9 July 2013). Stages one and two have already been published. [16,17]

\section{Method}

\section{Survey instrument}

The six-page survey included four Likert scales named interpersonal and communication skills (IPC), critical analysis skills, job-specific skills and self-management as per our previous publication. [17] Graduates rated items in each scale for importance and then rated their own skill level on a five-point scale, from no skills i.e. requiring training and development (rated zero) to excellent rated four. Each item was rated in turn for importance then skill level to promote understanding that comparisons were being made. Other questions covered current employment, sector, salary level, gender, type of work, how the job was found, and open-ended items asked about perceived gaps in skills and recommendations to inform future curriculum development.

\section{Survey sample}

The survey was emailed over a three-month period from February 2013, to 50 health service managers who had graduated within the last three years. Recent graduates were found through graduation lists for one large metropolitan university in New South Wales as former students of the bachelor's degree in HSM 2010-2012. Students currently enrolled into the Masters of Health Science (HSM) were also emailed and included graduates from a range of educational backgrounds. The limitations of such convenience sampling are noted in the discussion.

\section{Analysis}

The scaled items were checked for internal consistency using Chronbach's alpha. For the total 44 items internal consistency was good with a Chronbach's alpha coefficient of 0.926. Furthermore, all sub-scales achieved a satisfactory Chronbach's alpha over .7, (ranging from .822 to .915), suggesting good internal consistency, that they were measuring the same underlying construct. Other analysis included paired samples t-tests for comparison of importance and self-rated skills with $p$ set at 0.05 , two tailed test for an exploratory study.

\section{Results \\ Respondents}

A total of 42 responded, 15 males and 27 females, a response rate of $84 \%$. Twenty had completed an undergraduate degree from one metropolitan university, 20 from a variety of universities across New South Wales and two from overseas. Nearly half had worked in their current position only a year, eight less than a year, another eight up to two years, and five for over three years. (Some had worked in that job prior to 
Figure 1: Overall rating of each ES scale by recent graduates $(n=42)$

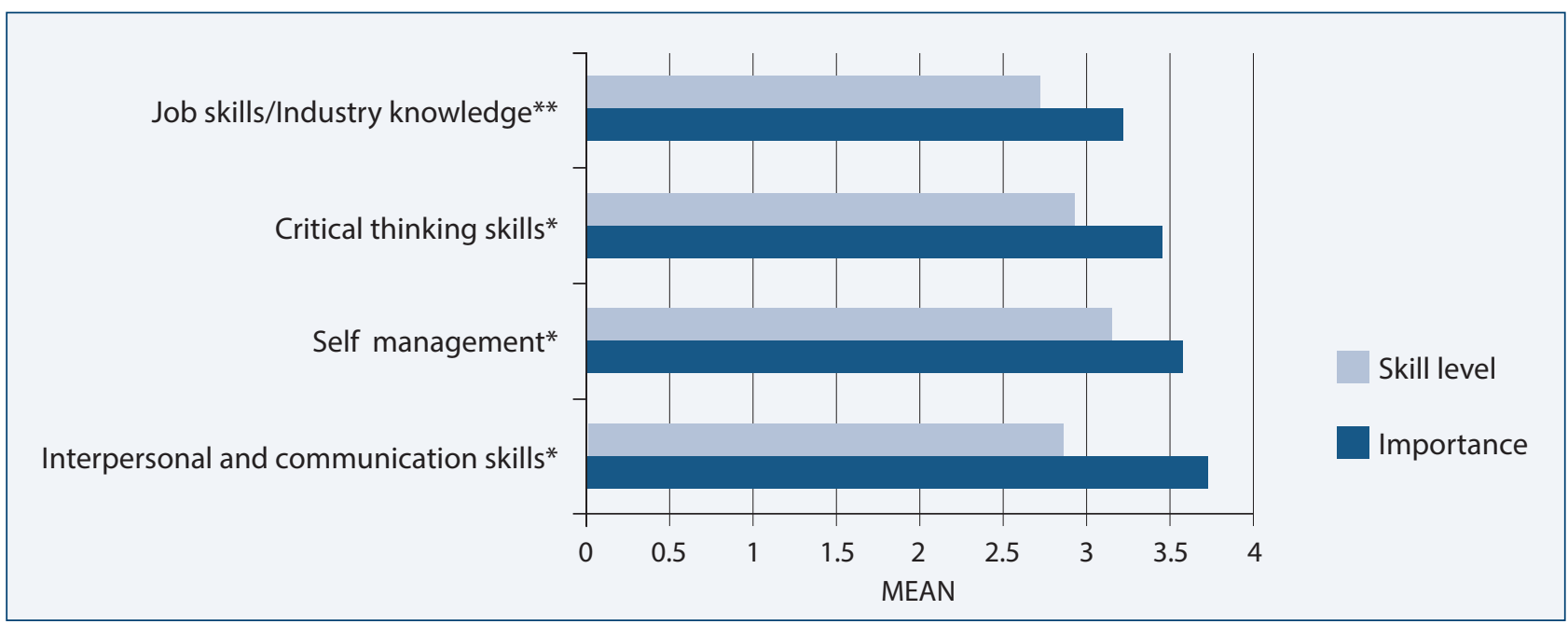

${ }^{*} p<0.001,{ }^{* *} p<0.01$

graduation, studying part-time.) The majority (88\%) worked fulltime, but only four held a permanent position.

Over one third were currently engaged in part-time postgraduate study, in a ratio of two females to one male. Six worked as quality managers, four in general management roles, seven as project officers, and the others in support roles, eg personal assistants to senior staff. Three quarters (32) worked for state government, three for local government, six worked for not for profit organisations and one worked in the private sector. Nearly half (45\%) earned in Australian dollars the salary range of $\$ 45-54999,31 \%$ $\$ 55-64999,19 \%$ over $\$ 65000$ and only four under $\$ 45000$, (working part-time), compared with the median new Australian graduate annual salary of $\$ 52000$. [28]

\section{Job search strategies}

The job search strategies that successfully secured recent graduates employment in HSM included finding out about the job from a university lecturer (29.3\%), advertisement on the internet $22 \%$, family/friends and university careers services both $9.8 \%$, work contacts or 'other' both $17 \%$, and print media only 7.3\%. Under 'other' two mentioned employer web sites which equated to less than $5 \%$. None found employment through careers fairs or employment agencies. Only three used more than one option.

\section{Figure 2: Importance of and self-rating of IPC $(n=42)$}

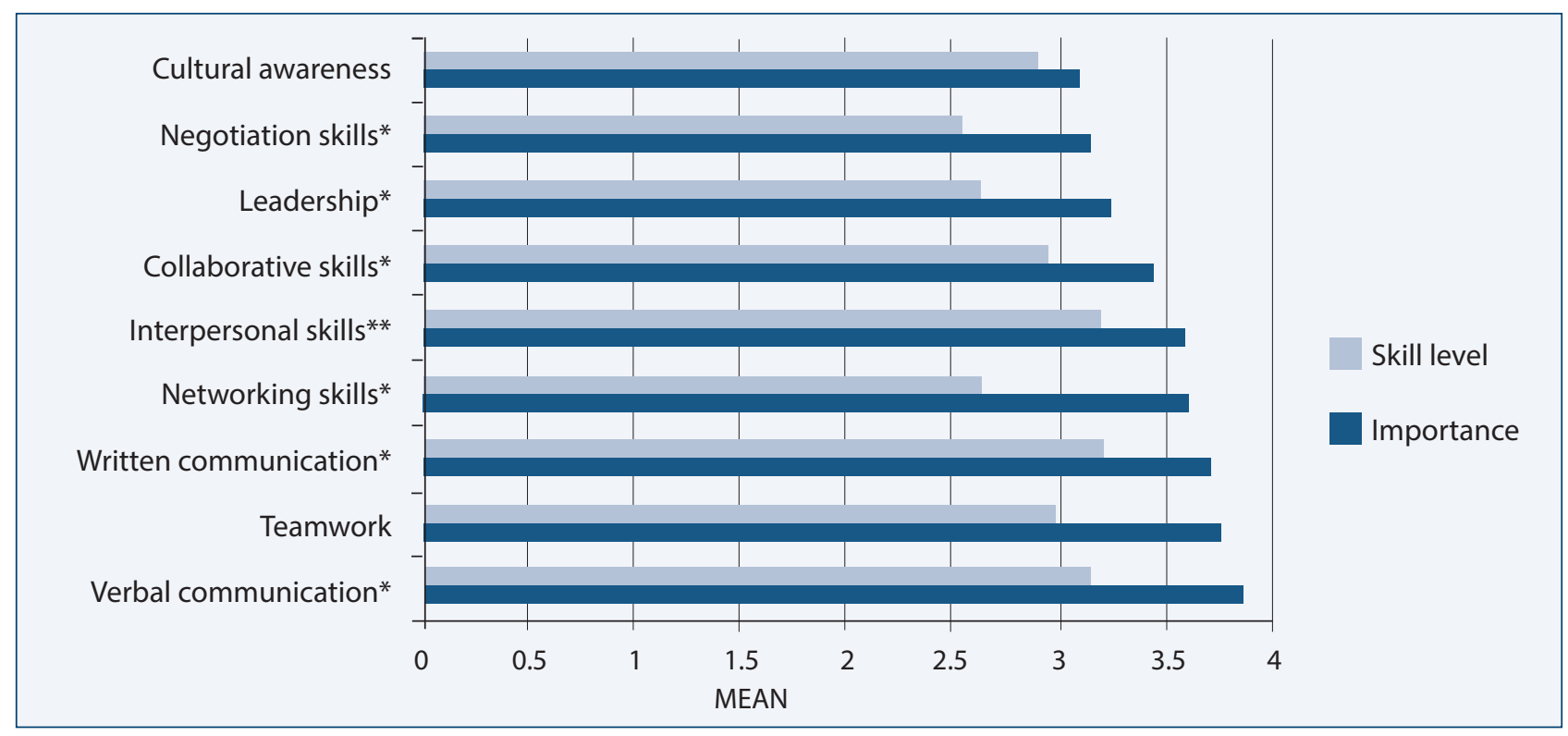

${ }^{*} p<0.001,{ }^{* *} p<0.01$ 
Figure 3: Importance of and self-rating of self-management $(n=42)$

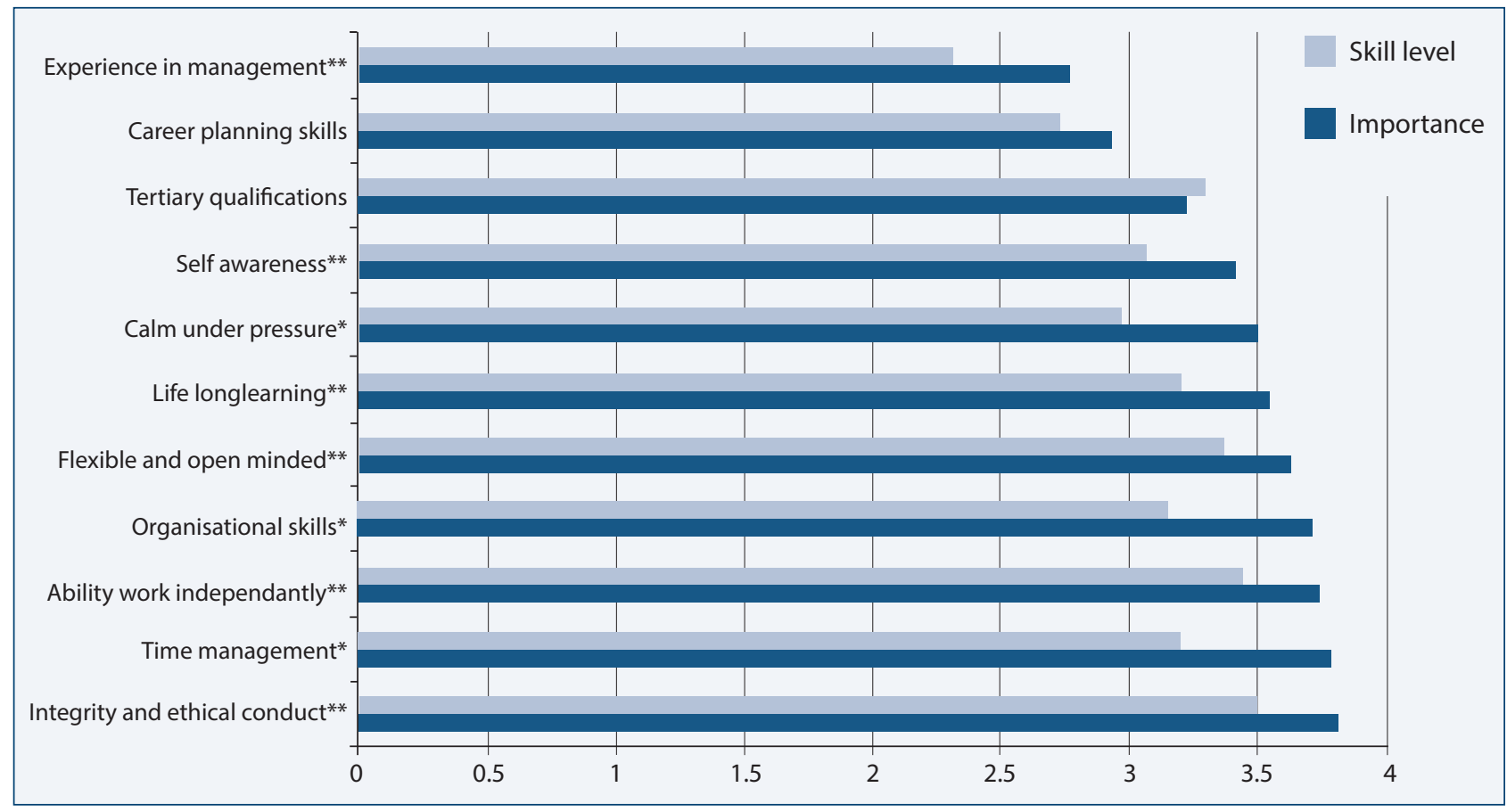

${ }^{*} p<0.001,{ }^{* *} p<0.01,{ }^{* * *} p<0.05$

\section{Rating of employability skills}

For each of the four scales, a total score was recorded by participants $(n=42)$, and comparison of mean scores for importance (the lower bar) of ES and self-rating by recent graduates (the upper bar) are depicted in Figure 1. This shows that IPC, self-management and critical thinking were the most important ES according to recent graduates. Job skills and industry knowledge were less important. Selfrating of skills achieved significantly lower mean scores than importance ratings on each sub-scale. The biggest gap between rating of importance and self-ratings was for IPC, then critical thinking, job skills and self-management skills.

Each scale will now be discussed in turn. For IPC (Figure 2) the most important skills for recent graduates were verbal communications skills, team working, written skills and networking. Leadership and negotiation skills were rated as least important. For all items on this scale except cultural awareness, graduates' ratings of importance were significantly higher than self-ratings. Self-rating was lowest

Figure 4: Importance of and self-rating of critical thinking $(n=42)$

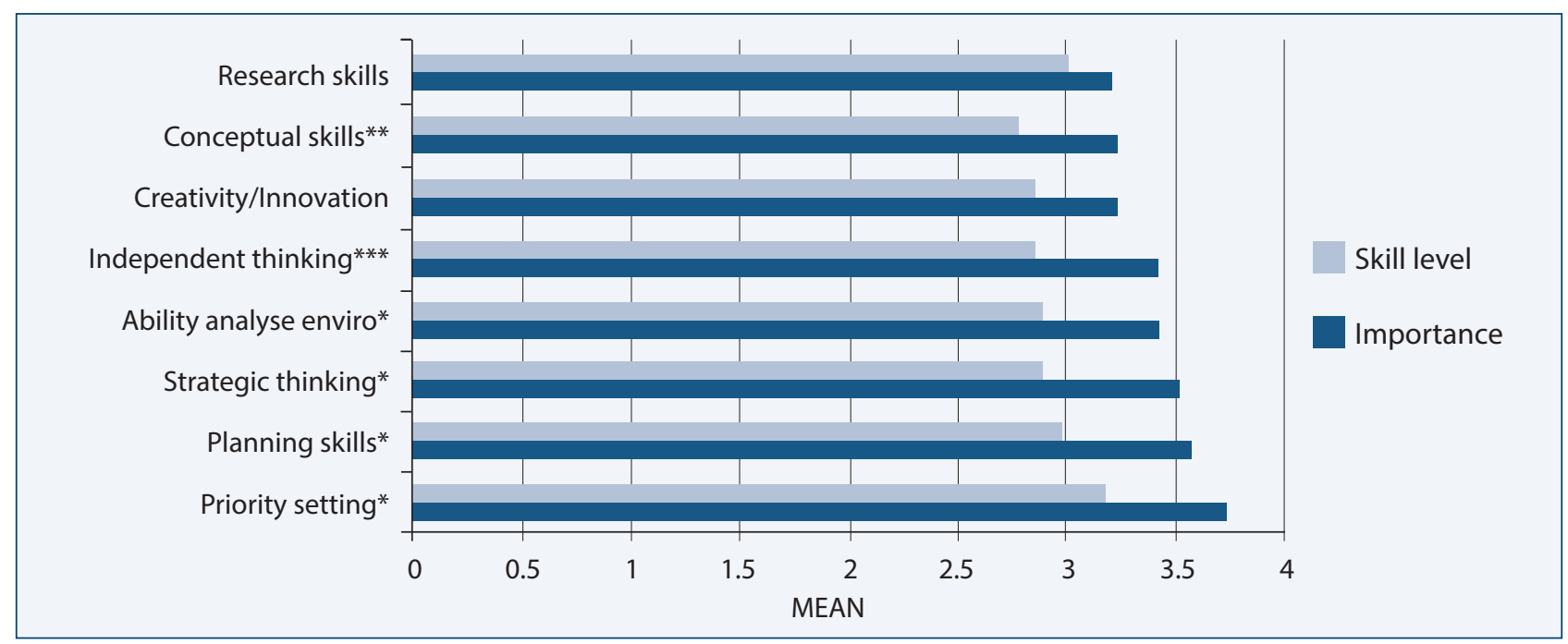

${ }^{*} p<0.001,{ }^{* *} p<0.01,{ }^{* * *} p<0.05$ 
for negotiating skills, leadership and networking, highest for interpersonal, written and verbal skills. The biggest skill gaps emerged for networking and teamwork.

In the self-management scale shown in Figure 3, the most important ES emerged as integrity and ethical conduct. After this, time management, the ability to work independently, organisational skills and being flexible and open minded were rated highly important with mean scores over 3.5. For all items self-rating mean scores were significantly lower than importance ratings except for tertiary qualifications and career planning. For career planning and tertiary qualifications no perceived skill gap was found. The biggest skill gaps emerged for being calm under pressure, time management and organisational skills.

For critical thinking skills the most important aspects for recent graduates (Figure 4) were priority setting, planning skills and strategic thinking, with mean scores of 3.5 or more. For all items except research skills and creativity and innovation, the differences between graduates' rating of importance were significantly higher than self-ratings. The biggest skill gaps emerged for planning skills and priority setting.

Figure 5 shows the most important job skills/industry knowledge items for recent graduates as computer and software skills and project management with mean scores over 3.5. For all items except administration, graduates'rating of importance was significantly higher than self-ratings. The lowest self-ratings were given to knowledge of the local population, operational management, budget/financial skills and change management. The highest self-ratings resulted for administration, computer and software skills. The biggest skill gap emerged for change management, project management and performance management.

Graduates were asked how well they felt university prepared them for the workplace. One stated poorly, three were unsure, $35(83.3 \%)$ said well and three felt university prepared them very well for their job. The most common response to an open ended question asking which aspects of higher education contributed most to skill development was placements $(n=15)$, for industry exposure, to gain understanding and experience of the health system, how it works and health terminology. This was followed by development of writing skills from 12 respondents, specifically report writing and data analysis (four each). Supportive lecturers with health system knowledge and relevant field experience, who for example kept up to date with developments in the work environment, and offered 'relevant and authentic assessments' that prepared them for the world of work, was mentioned by six. Working in groups/teams was also mentioned by six.

Aspects that needed improvement included longer placements $(n=11)$; greater emphasis on report writing and data analysis, grant applications, briefs, business cases, and critical analysis $(n=6)$; development of computing skills specifically use of Excel and exposure to health data systems, more financial management content, group and teamwork

Figure 5 Job skills and industry knowledge importance and self-rated skill levels

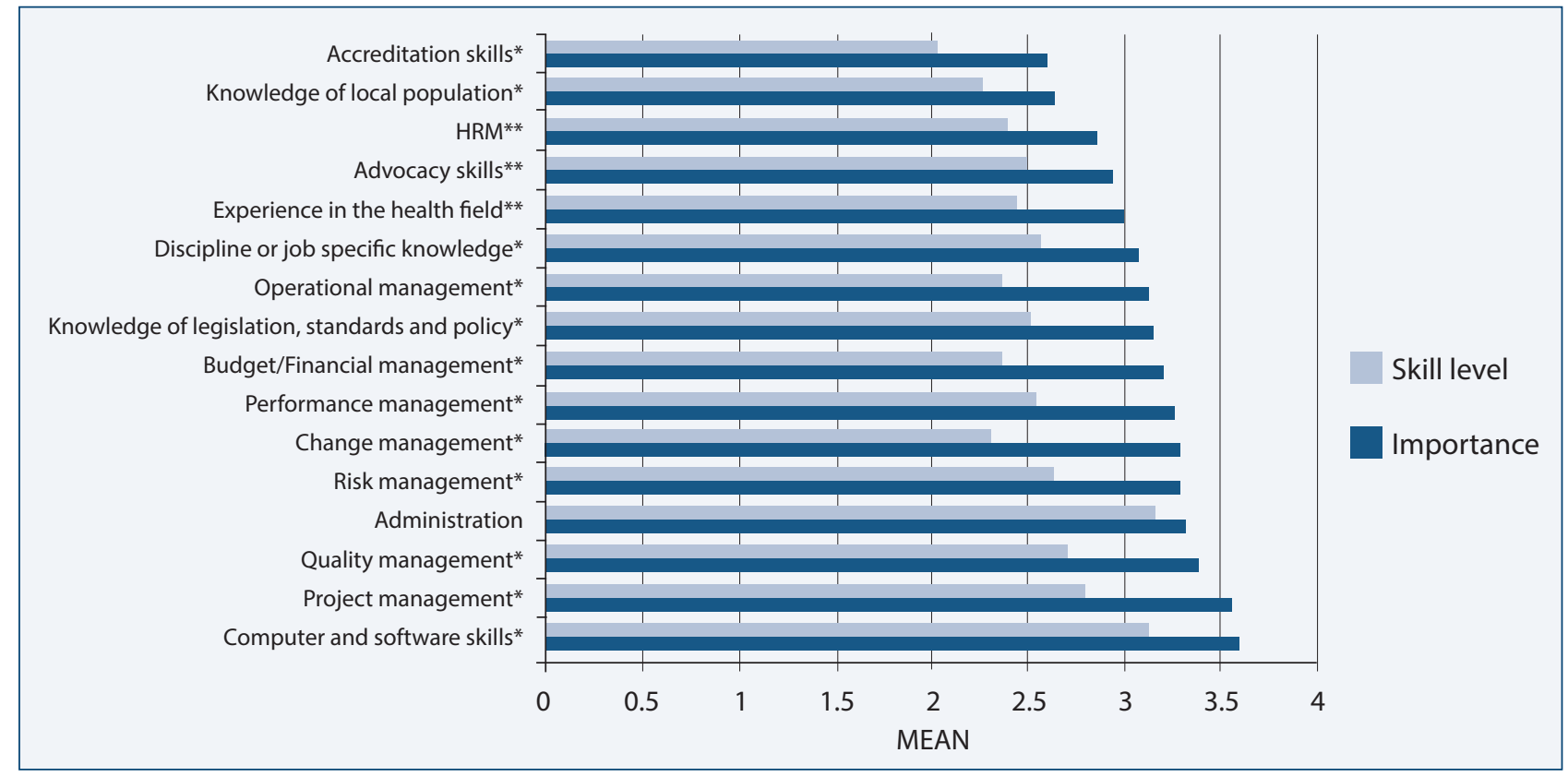

${ }^{*} p<0.001,{ }^{* *} p<0.01$ 
skill development, teaching of project management skills, and how to apply for jobs, (four responses each). Conflict resolution and managing people were also listed as needed by three graduates. The most common theme that emerged as a skill gap when commencing work in health management was lack of understanding and knowledge of the health system $(n=11)$. None of these respondents held a health related undergraduate degree. Knowledge of health software and data bases $(n=10)$ was the second most common response and in equal third place, writing skills, financial management and project management (four respondents each).

\section{Discussion}

Job search strategies of new managers in this study did not match the main ways employers advertise graduate vacancies in Australia: [4] none specified organisational websites heavily used by employers, mainly finding current positions through a university lecturer or internet employment sites. Also graduates felt that work experience placements gave them an advantage by helping develop ES, consistent with the literature. [6,7] These findings suggest that engagement of universities and employers could be mutually beneficial to improve job matching.

Undertaking post-graduate study was also seen as instrumental in progressing careers. Just over one third of survey respondents in comparison with the Australian average of $20 \%$, [4] were enrolled in post-graduate study, but this rate is lower than the United Kingdom rate of $60 \%$. [15] The low rate of permanent employment of respondents may serve as an incentive to develop skills through further study.

To further improve job matching, graduates views on the important ES that they need on the job revealed that IPC were the most important for new health managers, consistent with findings for all graduates from GCA [27] and our earlier study of health managers. [17] The ten most important individual ES for study participants, in rank order, emerged as verbal communication skills, integrity and ethical conduct, time management, teamwork, priority setting, ability to work independently, organisational skills, written communication skills, being flexible and open minded and networking. All of these would be thought of as generic rather than disciplinespecific skills, $[8,16]$ transferable to a variety of jobs. This well matched their employers' views. [17] The least important ES in this study were items in the job-specific scale that could be learnt on the job.

Recent graduates working in HSM consistently rated their own ES lower than the importance ratings for the same items and were able to identify skill gaps, consistent with previous findings. [11] The biggest gaps were for generic skills of networking, teamwork, planning and priority setting, and job specific skills in change management, budget/financial management, project management and performance management. Some of these can be taught at university and some on the job. Specific gaps confirmed in an open ended question included understanding of the health system, health terminology, report writing, computer skills, health-specific software and using Excel, managing people, business planning and writing grant applications. These are skills that higher education can address best in collaboration with the health industry. The way university prepares graduates for industry can also be informed by the finding that respondents identifying the need for longer placements, more practical emphasis in assessments, written assignments rather than knowledge quizzes, group project work, and greater input from industry. These findings are also consistent with the literature. $[7,18,21,28]$

\section{Implications of the study}

Ratings of importance and self-rated ES of recent graduates working in HSM point to specific gaps that universities can use to inform curriculum development and/or employers can address in ongoing professional development. Closer partnerships between universities and employers through employment placements can facilitate development of ES, improve job matching and HEl employment outcomes. How graduates find employment also may help explain problems experienced by employers finding enough suitable graduate applicants to employ.

\section{Further research}

Limitations of the study are that results are from new health managers in one state of Australia only. The small convenience sample limits generality of the findings and a larger replication study is warranted. Furthermore, a larger sample size would permit factor analysis to validate the scales used. Comparison of graduates' views with other stakeholders such as current students and employers would also be worthwhile, and research to confirm actual skills levels. It is also not certain that ES have the same meaning for different stakeholders eg priority setting may be seen as a self-management skill rather than a critical thinking skill by recent graduates.

\section{Conclusions}

Paying attention to the views of recent graduates working in the field can be useful to inform curriculum development. They rated generic ES as more important than job-specific skills and significant gaps were revealed. Rating of 
importance of ES for the HSM field is generally higher than graduates rating of their own skills with few exceptions, which revealed ES gaps. This new evidence about those skill gaps may stimulate academic discussion about curriculum development for HSM. Academics can also draw student attention to the ES requirements of employers and what recent graduates believe to be important in their jobs to foster engagement of students with learning materials. Furthermore, if curriculum is informed by discipline specific information, it may help improve employment outcomes. The need for partnerships of university with industry was confirmed because placements were found the best aspect of their course for ES development. However, resourcing, supervision, and greater academic engagement may be required to deliver authentic experiences supported by ESbased assessment.

\section{Acknowledgement}

Mr Paul Fahey, Senior Lecturer in Statistics, WSU for statistical advice and support.

\section{Competing interests}

The authors declare that they have no competing interests.

\section{References}

1. Department of Education, Science and Training (DEST). Employability skills for the future. A report by the Australian Chamber of Commerce and Industry and the Business Council of Australia for DEST. Canberra: DEST; 2002.

2. Semeijn J, Veldon R, Heijke H, Vlueten C, Boshuizen A. Competence indicators in academic education and early labour market success of graduates in health sciences. J Educ and Work. 2006:19(4): 383-413.

3. Liang Z, Short SD, Brown CR. Senior health managers in the new era: changing roles and competencies in the 1990s and the early 21st century. J Health Admin Ed. 2006; Summer:81-301.

4. Department of Education, Employment and Workplace Relations. Stage 1. Final Report Employability skills framework. Ithaca Group; 2012.

5. Oliver B, Whelan B, Hunt L, Hammer S. Accounting graduates and the capabilities that count: perceptions of graduates, employers and accounting academics in four Australian universities. J Teaching and Learning for Graduate Employability. 2011;2(1);2-21

6. Gedye S, Fender E, Chalkey B, Students undergraduate expectations and postgraduate experiences of the value of a degree. J Geog Higher Ed. 2004;28(3);381-96.

7. Crebert G, Bates M, Bell B, Patrick C, Cragnolini V. Developing generic skills at university, during work placements and in employment: graduates' perceptions. Higher Ed Res and Dev. 2004; 23(2):147-64

8. Graduate Careers Australia (GCA). The Report of the Graduate Outlook Survey: Employers' Perspectives on Graduate Recruitment. 2015. p.8. Available from: http://www.graduatecareers.com.au/ research/surveys/graduateoutlooksurvey/

9. Ridoutt L, Selby Smith C, Hummel K, Cheang C. What value do Australian employers give to qualifications? Available from: http:// www.ncver.edu.au/publications/1553
10. Oliver B, Hunt L, Jones, S, Pearce A, Hammer S, Jones S, Whelan B. The graduate employability indicators: capturing broader stakeholder perspectives on the achievement and importance of employability attributes. Proceedings of the Australian Quality Forum Quality in Uncertain Times. Gold Coast; 2010:89-95.

11. CBI. Changing the Pace. 2013. Available from: http://www.cbi.org uk/media/2119176/education_and_skills_survey_2013.pdf

12. Archer W, Davison J. Graduate employability: what do employers need and want? The Council for Industry and Higher Education; 2008. Available from: http:/www.cihe-uk.com

13. Hinchliffe GW, Jolly A. Graduate identity and employability. BERJ. 2014.DOI: $10.1080 / 01411926.2010 .482200$

14. Tymon A. The student perspective on employability. Studies in Higher Ed. 2011.doi10.1080/03075079.2011.604408

15. Commission for Employment and Skills. National Employers Survey 2013: UK Results. Available from: https://www.gov.uk/government/ uploads/system/uploads/attachment_data/file/327492/evidencereport-81-ukces-employer-skills-survey-13-full-report-final.pdf

16. Messum D, Wilkes L, Jackson D. Employability skills: essential requirements in health manager vacancy advertisements. A Pac J Health Manag. 2011;6:22-28.

17. Messum D, Wilkes $L$, Jackson D. What employability skills are required of new health managers? A Pac J Health Manag. 2015; 10(1):28-35

18. Ferns S. Graduate employability: teaching staff, employer and graduate perceptions. In Proceedings of the Australian Collaborative Education Network National Conference. Springvale; 2012. p.77-87. Available from: http://hdl.voced.edu.au/10707/259614.

19. Ainsworth $M$, Motley $C$. The value of management education: views of graduates on the benefits of doing a MBA. Higher Ed. 1995;30(2);175-187.

20. The Dearing Report. Higher Education in the Learning Society 1997 : Main report of the National Committee of Inquiry into Higher Education. 1997. Available from: http://www.educationengland. org.uk/documents/dearing1997/dearing1997.html

21. Kennely $M$, Jackling $B$. the acquisition of generic skills of culturally diverse student cohorts. Accounting Ed: An Int J. 2011;20(6):606-23.

22. Moreau MP, Leathwood C. Balancing paid work and studies: working (class) students in higher education. Studies in Higher Ed. 2006;31(1):23-42.

23. Tomlinson M. The degree is not enough: students perceptions of the role of $\mathrm{HE}$ credentials for graduate work and employability. Brit J Soc Ed. 2008;29(1):49-61.

24. Brooks R, Everett $\mathrm{G}$. the predominance of work-based training in young gradates learning. J Ed and Work. 2008;21(1):61-73.

25. Storen LA, Aamodt PO. The quality of higher education and employability of graduates. Quality in Higher Ed. 2010;16(3); 207-313.

26. Wickramasinghe V, Perera L. Graduates', university lecturers' and employers' perceptions towards employability. Education and Training. 2010;52(3):236-244.

27. Graduate Careers Australia (GCA). The Report of the Graduate Outlook Survey: Employers' Perspectives on Graduate Recruitment. 2013. Available from: http://www.graduatecareers.com.au/ wp-content/uploads/2014/03/Graduate_Outlook_2013.pdf

28. Graduate Careers Australia. Where grads go. 2015. Available from: http://www.graduatecareers.com.au/wp-content/uploads/2015/05/ GradsGo2015.pdf

29. Wilton N. The impact of work placements on skill development and labour market outcomes for business and management graduates. Studies in Higher E. 2012;37(5):603-620. 